фазе трех пар листьев; на элитных посевах при широкорядном посеве с нормой высева 0,9 млн/га и декапитацией растений в фазе трех пар листьев; на репродукционных посевах при широкорядном посеве 45 см с нормой высева 1,2 млн/га и декапитацией растений в фазе трех пар листьев.

V. Dimitriev, L. Shashkarov, A. Lozhkin

\title{
ON THE IMPROVEMENT OF TECHNOLOGY ELEMENTS OF CANABIS SATIVA L. VARIETIES CULTIVATION IN THE CONDITIONS OF FOREST-STEPPE ZONE OF THE CHUVASH REPUBLIC
}

Key words: hemp; varieties; yield; architectonics; seed productivity; decapitation; seeding rate; seed reproduction; productivity structure.

\section{Authors' personal details}

1. Dimitriev Vladislav, Candidate of Agricultural Sciences, associate Professor of the Department of agriculture, crop production, plant breeding and seed production, Doctor of Chuvash State Agricultural Academy, 428032, Cheboksary, Karla Marksa st., 29, e-mail: dimitrieff.vladislaw@yandex.ru.

2. Shashkarov Leonid, Doctor of Agricultural Sciences, Professor of the Department of agriculture, crop production, plant breeding and seed production, Doctor of Chuvash State Agricultural Academy, 428032, Cheboksary, Karla Marksa st., 29, e-mail: Leonid.shashkarow@yandex.ru.

3. Lozhkin Alexander, Candidate of Agricultural Sciences, associate Professor of the Department of agriculture, crop production, plant breeding and seed production, Doctor of Chuvash State Agricultural Academy, 428032, Cheboksary, Karla Marksa st., 29, e-mail: lozhkin_tmvl@mail.ru.

The article considers the prospects of introduction of new elements of hemp cultivation technology in order to accelerate the production of seeds and increase the yield of stems, seeds and fiber. It is revealed that the forced reproduction of seeds of hemp varieties should be organized at the following optimal parameters of the basic elements of agricultural cultivation and seed production: in the nursery of primordial seeds with a wide-row sowing of $70 \mathrm{~cm}$ with a seeding rate of $0,3 \mathrm{million} / \mathrm{ha}$ and

(C) Димитриев В.Л., Шашкаров А.Г., Ложкин А.Г. decapitation of plants in the phase of 3 pairs of leaves; on the site of original seeds with a wide-row sowing of $70 \mathrm{~cm}$ with a seeding rate of 0,6 million/ha and decapitation of plants in the phase 3 pairs of leaves; on elite crops with a wide-row sowing seeding rate of 0,9 million/ha and decapitation of plants in the phase of 3 pairs of leaves; on reproductive crops with wide-row sowing $45 \mathrm{~cm}$ with a seeding rate of 1,2 million/ha and decapitation of plants in the phase of 3 pairs of leaves.

УДК 712.4581 .93

DOI: 10.31563/1684-7628-2019-52-4-24-30

Л.М. Ишбирдина, Л.Н. Блонская, А.Ш. Тимерьянов, С.И. Конашова, С.И. Муфтахова

\section{ФЛОРА ГАЗОНОВ ГОРОДА УФЫ}

Ключевые слова: газоны; анализ флоры; эколого-ценотические группы видов; спектр жизненных форм; гемеробия; активность видов.

Введение. Газоны являются самыми распространёнными площадями озеленения. Значение газонов не ограничивается только созданием эстетичных пространств объектов ландшафтной архитектуры, газонные травянистые сообщества выполняют важные экологические функции: задерживают пыль [7], увлажняют и очищают городской воздух $[2,3]$, аккумулируют тяжелые металлы [6], закрепляют почву, предотвращают эрозийные процессы. К городским газонам 
относят площади, на которых были проведены мероприятия по созданию газонной дернины, это возможно путем посева газонных травосмесей, укладки рулонного газона, гидропосева на труднодоступных участках (например, откосах дорог, склонах). Однако часто после посева газонной травосмеси уход за формирующимся травяным покрытием сводится лишь к укосам, проводимым в лучшем случае раз в месяц. На таких участках, расположенных на второстепенных улицах, во дворах, на промплощадках, отсутствует полив, подкормка, землевание, известкование, что отрицательно сказывается как на общем проективном покрытии газонных трав, так и на флористическом составе данных площадей. Ослабленные газонные злаки не могут составить конкуренцию рудеральным и лугово-рудеральным видам, поэтому через несколько лет флора таких газонов обогащается за счет внедрившихся синантропных видов. Если при этом добавляются и другие антропогенные факторы - вытаптывание, засоление противогололедными реагентами, загрязнение в результате выбросов промышленных предприятий, то на площадях, которые были когда-то засеяны газонными травами, возникают рудеральные сообщества. При изучении разнообразия флоры газонов и оценке тенденций ее динамики важную роль играет использование экологических и ценотических характеристик как некоторого многомерного признакового пространства, организованного в первую очередь условиями среды. В этом пространстве исследуются эколого-ценотические ареалы видов и виды со сходными типами ценоареалов объединяются в эколого-ценотические группы. Эколого-ценотические группы (ЭЦГ) - группы растений, сходных по отношению к совокупности экологических факторов и приуроченных к местопроизрастаниям определенного типа [8].

Целью и задачами настоящей работы было изучение флоры газонов г. Уфы по видовому составу выделенных ЭЦГ. При этом для сравнения были изучены собственно сообщества газонов и рудерализированнные и рудеральные площади, на которых ранее проводились работы по устройству газонов, но не обеспечивался последующий уход.

Материалы и методы исследования. Анализ флоры проводился на основе геоботанического обследования газонов города, выполненного в 2006-2008 гг. Для характеристики выделенных ЭЦГ использованы следующие признаки: спектр жизненных форм, спектр гемеробии, шкала активности видов. Соотношение разных жизненных форм растений в растительных сообществах является важным показателем состояния растительного покрова. Жизненная форма - это комплекс морфологических признаков, связанных с ритмом развития, отражающих приспособленность вида к современным и прошлым условиям среды в целом, ко всему комплексу факторов местообитания [5]. Система жизненных форм К. Раункиера (1934) хорошо характеризует приспособленность различных видов растений к перенесению неблагоприятных погодных и климатических условий в зимний период [5]. Гемеробия видов флоры и растительных сообществ в целом отражает результат всех видов антропогенного влияния на экосистему. Чем интенсивнее антропогенное влияние, тем выше уровень синантропности видов. Уровень гемеробии растет от особо чувствительных к изменениям естественных сообществ, где полностью или частично отсутствует антропогенное влияние, через умеренно уязвимые сообщества лесов, лугов, остепненных лугов и степей с экстенсивным антропогенным влиянием и далее к сообществам, испытывающим интенсивный антропогенный пресс. Крайней стадией проявления антропогенного воздействия являются искусственные местообитания, асфальтовые или бетонные покрытия, мусорные свалки, отвалы, карьеры и другие техногенные сооружения [10-13]. При анализе флоры газонов была использована шкала гемеробии по 7 градациям [9-13]:

$a$ - агемеробные виды, не выносят антропогенное влияние;

$o$ - олигогемеробные виды лесов, лугов, верховых болот и т. д., выносят очень незначительное антропогенное влияние;

$m$ - мезогемеробные виды лесов, лугов, остепненных лугов и степей, выносят экстенсивное антропогенное влияние;

$b-\beta$-эугемеробные виды лугов и лесов с интенсивным уходом, выносят эвтрофикацию, известкование, незначительное нарушение грунта;

c - $\alpha$-эугемеробные виды удобряемых лугов, деградирующих лесов, полевые сорняки;

$p$ - полигемеробные виды, выращиваются в культуре и являются типичными рудеральными растениями, выносят сильные и частые нарушения местообитаний;

$t$ - метагемеробные виды приурочены к полностью деградировавшим экосистемам и искусственным сообществам.

Активность видов оценивалась как усреднённое значение встречаемости вида на основе широты его эколого-ценотической амплитуды [1] по пятибалльной шкале. Значение баллов: 1 - вид встречается очень редко (неактивные виды - по шкале Я. Дидуха [4]); 2 - вид встречается редко в нередких типах сообществ или 
обыкновенен в очень редких типах сообществ (малоактивные); 3 - вид встречается довольно часто в редких типах сообществ или реже в распространенных (среднеактивные); 4 - вид встречается часто в нередких типах сообществ (высокоактивные); 5 - вид обыкновенен во многих из часто и очень часто встречающихся типах сообществ (высокоактивные).

Результаты исследования. Все разнообразие флоры газонов города можно объединить в 4 ЭЦГ, объединяющих виды со сходным характером распределения в растительных сообществах. Принадлежность вида к той или иной ЭЦГ условна и несет вероятностный характер. При низком постоянстве ценоареал большинства видов значительно шире. При отнесении вида к ЭЦГ из круга сообществ, в которых встречается вид, учитывались те, в которых вид постоянен (имеет экологический оптимум и встречается с постоянством V-III класса). При этом у некоторых видов под влиянием антропогенных нарушений сообществ экоценоареалы могут расширяться, а у других, напротив, сужаться. Например, неофит Elscholtzia ciliata, встречающийся обычно в рудеральных сообществах районов города с одноэтажной застройкой, проникает и в газонные сообщества в составе высеваемых травосмесей. Таким образом, предложенная система ЭЦГ видов характеризует закономерности распределения их в условиях антропогенных нагрузок на сообщества газонов, которые сложились в Уфе.

Экоценогруппы названы по характерному представителю.

Festuca pratensis. ЭЦГ луговых видов (таблицы 1,2$)$, в нее включено большее количество видов из семейств Poaceae (12), Asteraceae (8), Fabaceae (6).

Таблица 1 Распределение видов флоры газонов по ведущим семействам

\begin{tabular}{|c|c|c|c|c|}
\hline \multirow{2}{*}{ Семейство } & \multicolumn{4}{|c|}{ ЭЦГ } \\
\hline & Festuca pratensis & Taraxacum officinale & Chenopodium album & Bidens tripartita \\
\hline Poaceae & 12 & 4 & 7 & 5 \\
\hline Asteraceae & 8 & 7 & 8 & 2 \\
\hline Brassicaceae & 1 & 6 & 4 & 2 \\
\hline Rosaceae & 4 & 2 & 1 & 1 \\
\hline Caryophyllaceae & 1 & 4 & 1 & 1 \\
\hline Fabaceae & 6 & 7 & 1 & - \\
\hline Apiaceae & 4 & 1 & 1 & - \\
\hline Lamiaceae & 2 & 5 & 6 & - \\
\hline Polygonaceae & - & 8 & 4 & 3 \\
\hline Ranunculacea & 4 & - & - & 1 \\
\hline Malvaceae & - & 1 & 6 & - \\
\hline Amaranthaceae & - & - & 7 & - \\
\hline Chenopodiaceae & - & - & 3 & 5 \\
\hline Plantaginaceae & - & 4 & - & - \\
\hline
\end{tabular}

Таблица 2 Количественный состав ЭЦГ флоры газонов и относительная активность видов в ЭЦГ

\begin{tabular}{|l|c|c|c|c|c|c|}
\hline \multirow{2}{*}{\multicolumn{1}{|c|}{ ЭЦГ }} & \multirow{2}{*}{ Всего видов в ЭЦГ } & \multicolumn{5}{c|}{ Активность видов, \% в ЭЦГ } \\
\cline { 3 - 8 } & & 1 балл & 2 балла & 3 балла & 4 балла & 5 баллов \\
\hline Festuca pratensis & 51 & 7,8 & 39,2 & 33,3 & 3,9 & 15,7 \\
\hline Taraxacum officinale & 55 & 5,5 & 20,0 & 38,2 & 14,5 & 21,8 \\
\hline Chenopodium album & 65 & 29,2 & 24,6 & 30,8 & 6,2 & 9,2 \\
\hline Bidens tripartita & 21 & 19,0 & 38,1 & 19,0 & 14,3 & 9,5 \\
\hline
\end{tabular}

В составе видов данной ЭЦГ доминируют гемикриптофиты - $94 \%$.

Редко и очень редко встречается $46 \%$ видов (Ranunculus monophyllus, Sanguisorba officinalis), $33 \%$ видов проявляют среднюю активность (Cenolophium denudatum, Knautia arvensis, Stellaria graminea, Prunella vulgaris, Agrostis tenuis и др.) и лишь $19 \%$ (10 видов) не редки или вполне обычны (Carum carvi, Knautia arvensls, Bromopsis inermis, Dactylis glomerata, Festuca pratensis, F. rubra, Lysimachia nummularia, Poa pratensis, Pastinaca sylvestris и др.). В данной ЭЦГ велика доля видов с широким спектром гемеробии - олиго-мезо-эугемеробов (35,3 \%): Pimpinella saxifraga, Achillea cartilaginea, Centaurea scabiosa, Inula britannica, Stellaria graminea, Trifolium hybridum, Glechoma chederacea и др. Мезо-эугемеробы составляют 29,4% (Carum carvi, Trifolium pratense, Prunella vulgaris и др.). Олигомезогемеробы составляют 15,7 \% видов (Centaurea scabiosa, Inula britannica, Lanthyrus pratensis, Lotus corniculatus и др.). 
Taraxacum officinale. Эвритопная ЭЦГ, объединяющая виды лугово-рудеральных сообществ класса Molinio-Arrhenatheretea Тх. 1937 (союза Cynosurion R. Tx. 1947.), классов Plantaginetea majoris R. Tx. et Prsg. in R. Tx 1950, Agropyretea repentis Oberd., Th. Muller et Gors in Oberd. et al. 1967, Artemisietea vulgaris Lohm. et al. ex von Rochow 1951. Наибольшую представленность в этой ЭЦГ имеют виды семейств Polygonaceae (14,5\%), Asteraceae (12,7\%), Fabaceae $(12,7 \%)$.

В спектре жизненных форм преобладают гемикриптофиты (63,65 \%) и криптофиты (14,5\%). Редких и очень редких по встречаемости видов зарегистрировано 14 (Artemisia abrotanum, Cynoglossum officinale, Rorippa sylvestris, Plantago urvillei, Rumex longifolius и др.) Наибольшее количество видов данной ЭЦГ встречаются с баллом: 3 (21 вид.): Barbarea vulgaris, Rorippa austriaca, Cerastium holosteoides, Euphorbia semivillosa, Mentha arvensis, Phlomis tuberosa и др. Обыкновенных видов с баллом встречаемости 4 и 5 в данной ЭЦГ зарегистрировано максимальное количество относительно других групп - 16 видов: Amoria repens, Taraxacum officinale, Achillea miliefolium, Elytrigia repens, Polygonum avicularis, Rumex crispus и др. В ЭЦГ преобладают мезо-эугемеробы - 38,2 \% (Picris hieracioides, Cichorium intybus, Barbarea vulgaris, Cerastium holosteoides, Oberna procumbens, Oberna beben, Euphorbia semilillosa, Medicago sativa, Amoria repens и др.) и велика доля видов широкого спектра гемеробии: олиго-мезо-эугемеробов $(12,7 \%)$ (Achilliea millefolium, Medicago falcata, Plantago lanceolata, P.media, Agrostis stolonifera, Rumex acetosella и др.) и эуполигемеробов $(12,7 \%)$ (Poa annua, Rumex confertus, R. thyrsiflorus, Polygonum neglectum и др.). В состав видов данной ЭЦГ включено 9 неофитов (Lathyrus tuberosa, Medicago sativa, Lavatera thuringiaca, Lolium perenne и др.) и 1 археофит (Convolvulus arvensis).

Chenopodium album. Эвритопная ЭЦГ видов сообществ начальных стадий сукцессий с преобладанием однолетников порядков Sisymbrietalia J. Tx. in Matuszkiewicz 1962 и Polygono-Chenopodietalia J. Tx. in Lohmeyer et al. 1962. Такие сообщества возникают на площадях, подготовленных для создания газонов, но не засеянных газонными травосмесями, или засеянных газонными травами с очень плохой всхожестью. Т. е. на свежих нарушенных местообитаниях или на площадях со свежезавезенным грунтом.

Наибольшее количество видов представлено в семействах Asteraceae (12,3\%), Amaranthaceae $(10,7 \%)$, Poaceae $(10,7 \%)$, Lamiaceae $(9,2 \%)$,
Malvaceae (9,2 \%), Brassicaceae (6,2 \%), Polygonaceae $(6,2 \%)$. При этом Amaranthaceae, Lamiaceae, Malvaceae, Brassicaceae и Polygonaceae являются «рудеральными» семействами.

В спектре жизненных форм преобладают терофиты $-81,5 \%$.

$30,7 \%$ видов проявляют среднюю активность (балл 3) (Amaranthus blitoides, Chenopodium suecicum, Vicia hirsuta и др.). Нередких и обыкновенных видов данной ЭЦГ (4,5 баллов активности) зарегистрировано 10 (Amaranthus retroflexus, Brassica campestris, Capsella bursapastoris, Stellaria media, Chenopodium album, Sinapis arvensis, Fallopia convolvulus, Polygonum lapathifolium, Viola arvensis).

$52 \%$ видов группы - $\beta$-эуполигемеробы, $32,3 \%$ видов - $\alpha-\beta$-эуполигемеробы, эти группы видов способны выносить значительное антропогенное влияние. Это в основном эргазио- и эфемерофиты (Ambrosia trifida, Calendula officinalis, Chamomilla recutita, Helianthus annus и др.). В данной ЭЦГ зарегистрировано большое количество видов-неофитов и археофитов, в том числе 18 эпекофитов (Amaranthus lividus, Raphanus raphanistrum, Chenopodium urbicum, Euphorbia helioscopia), 21 эргазиофит (Chamomilla recutita, Solanum tuberosum, Lycopercicon esculentum и др.), 4 эфемерофита (Galinsoga parviflora, Portulaca oleracea), 28 археофитов (Centaurea cyanus, Sonchus oleraceus, Brassica campestris, Capsella bursa-pastoris, Cannabis ruderalis, Galeopsis bifida, G. ladanum, Vicia hirsuta).

Bidens tripartita. Эвритопная группа видов нитрофильных сообществ влажных и переувлажненных местообитаний класса Bidentetea tripartiti R. Tx., Lohm. et Prsg. 1950. Такие сообщества возникают на переувлажненных площадях, отведенных под устройство газонов. Описаны в микрорайоне Дема. В ЭЦГ по численности также преобладают виды «рудеральных» семейств Chenopodiaceae (23,8 \%), Polygonaceae $(14,3 \%)$, отмечена высокая доля видов семейства Poaceae $(23,8 \%)$,

В спектре жизненных форм преобладают терофиты $-81 \%$.

$57 \%$ видов встречаются с низкой активностью (1,2 балла): Chenopodium acerifolium, Ch. ficifolium, Eragrostis pilosa, Potentilla supina, Polygonum mite, Rumex maritimus и др.). 4 вида зарегистрировано с баллом активности 3 (Rorippa palustris, Chenopodium rubrum, Juncus compressus, Bidens cernua) и 5 видов с 4 и 5 баллами активности (Bidens tripartita, Chenopodium glaucum, Echinochloa crus-galli, Setaria glauca, S. viridis). В спектре гемеробии преобладают виды 
широкой амплитуды гемеробности: 38 \% - эуполигемеробы (Atriplex micrantha, Chenopodium glaucum, Ch. rubrum, Setaria glauca, S. viridis, Echinochloa crus-galli), 28,6 \% видов - олигомезо-эугемеробы (Bidens cernua, B. tripartita, Roripp brachycarpa, Juncus compressus, Polygonum minus и др.)

В составе ЭЦГ зарегистрировано 8 видовпришельцев, в т. ч. 2 эпекофита (Chenopodium glaucum, Setaria glauca), 1 агрифит (Eragrostis plosa), 3 археофита (Chenopodium rubrum, Echinochloa crus-galli, Setaria viridis).

Выводы. Флора площадей, отведенных под газоны на территории города Уфы, представлена 192 видами, относящимися к 31 семейству. Преобладающие по количеству видов семейства в рассмотренных ЭЦГ значительно различаются, так в сообществах типичных городских газонов со слабым вытаптыванием и хорошим уходом (ЭЦГ Festuca pratensis) доминируют семейства Poaceae, Asteraceae, Fabaceae, Rosaceae, Apiaceae. На газонах, испытывающих значительное антропогенное воздействие - вытаптывание, засоление и не обеспеченных достаточным уходом (ЭЦГ Taraxacum officinale), большое количество видов относится к «рудеральным» семействам Polygonaceae, Asteraceae, Fabaceae, Brassicaceae, Lamiaceae. На площадях, отведенных под устройство газонов, где не произошло развитие злакового сообщества из-за низкой всхожести газонных травосмесей или прекращения работ по устройству газонов после нарушения почвы (ЭЦГ Chenopodium album), преобладают рудеральные виды семейств Asteraceae, Poaceae, Amaranthaceae, Lamiaceae, Malvaceae, Polygonaceae. На влажных и переувлажненных площадях, отведенных под газоны, также доминируют рудеральные виды семейств
Poaceae, Chenopodiaceae, Polygonaceae. Значительны различия выделенных ЭЦГ и по спектру жизненных форм. В стабильных ЭЦГ Festuca pratensis и Taraxacum officinale доминируют гемикриптофиты, а в рудеральных ЭЦГ Chenopodium album и Bidens tripartita значительна доля рудеральных одно- и двулетников. Анализ спектров гемеробии видов ЭЦГ также продемонстрировал значительные отличия. В ЭЦГ Festuca pratensis преобладают олиго-мезо- $\alpha$-эугемеробы, в ЭЦГ Taraxacum officinale доминируют мезо-эугемеробы, а в ЭЦГ Chenopodium album и Bidens tripartita большая часть видов рудеральные и полурудеральные $\beta$-эуполигемеробы. В ЭЦГ Taraxacum officinale, Chenopodium album и Bidens tripartita зарегистрировано большое количество видов-неофитов.

Таким образом, проведенное исследование показало удобство метода выделения экоценогрупп для анализа флоры экологически пестрых и разнообразных по антропогенному воздействию площадей. Группы естественны и включенные в них виды как единообразно распределены в экологическом пространстве, так и обладают сходством тенденций изменения активности при усилении режима антропогенного влияния на газоны. С практической точки зрения большого внимания заслуживают газонные площади с выделенными ЭЦГ Taraxacum officinale, Chenopodium album и Bidens tripartita как наиболее засоренные рудеральными видами, здесь необходимо проведение ряда мероприятий для создания сомкнутых травяных покрытий: реконструкция и капитальный ремонт площадей с посевом качественных газонных травосмесей, проведение регулярных укосов для снижения численности рудеральных малолетних видов, своевременные подкормки и полив.

\section{Библиографический список}

1. Бурда, Р.И. Антропогенная трансформация флоры [Текст] / Р.И. Бурда. Киев: Наукова думка. 1991. 169 с.

2. Газоны. Научные основы интродукции и использования газонных и почвопокровных растений [Текст]: сборник научных трудов / Отв. ред. Н.В. Цицин; Главный ботанический сад. М.: Наука, 1977. 244 с.

3. Гречушкина-Сухорукова, Л.А. Микроклиматические особенности газонных ценозов в степной зоне [Текст] / Л.А. Гречушкина-Сухорукова // Вестник АПК Ставрополья. 2014. № 2 (14). C. 190-195.

4. Дидух, Я.П. Проблемы активности видов растений [Текст] / Я.П. Дидух // Ботанический журнал. 1982. Т. 67. № 7. С. 925-935.
5. Иванов, Е.С. Биоморфологическая структура флоры природного историко-архитектурного и рекреационного комплекса - усадьба «Воронцово» г. Москвы [Текст] / Е.С. Иванов, Н.В. Авдеева, Т.В. Кременецкая // Российский научный журнал. 2011. № 22. С. 290-296.

6. Кайгородов, Р.В. Загрязнение почв придорожных газонов г. Перми тяжелыми металлами, их распределение в вегетативных и генеративных органах и влияние на фертильность и линейные размеры пыльцевых зерен Taraxacum officinale s.L. [Текст] / Р.В. Кайгородов, Л.В. Новоселова, Е.В. Мозжерина // Вестник Пермского университета. 2010. Вып. 3. С. 30-35.

7. Лаптев, А.А. Газоны [Текст] / А.А. Лаптев. Киев: Наукова думка, 1983. 176 с. 
8. Назаренко, Н.Н. Эколого-ценотические группы как фитоиндикаторы биотопов лиственных лесов северной степи Украины [Текст] / Н.Н. Назаренко // Вестник Тамбовского университета. Серия: Естественные и технические науки. 2014. Т. 19. № 5. С. 1324-1327.

9. Frank D., Klotz S. Biologisch-oekologische Daten zur Flora DDR. Martin-Luther-Universitaet, Halle - Wittenberg. Halle (Saale). 1990. 167 S.

10. Klotz S. Die ruderalgesselschaften eines neubaugebietes - ihre verbeitung und kombination // Acta bot. Slov. Acad. Sci. Slovacae. Ser. A. 1984. №.1. S. 111-125.

11. Kunick D. Zonietung des Stadtgebietes von Berlin (West). Ergebnisse Floristischer Untersuchung // Gen. Schriftenr. d.Fachber. Landschaftsentwicklung u. Umweltforsch. 1982. № 14. S. 1-164.
12. Мартынова, М.В. Влияние сезона рубки на формирование высопродуктивных липовых насаждений [Текст] / М.В. Мартынова, Р.Р. Султанова, С.В. Мартынова // В сборнике материалов Международной научно-практической конференции: Современная наука - агропромышленному производству. Тюмень: Государственный аграрный университет Северного Зауралья. 2014. C. $45-48$.

13. Sultanova, R.R. Evaluation of ecological potential of forests / R.R. Sultanova, K.M. Gabdrahimov, A.F. Khayretdinov, S.I. Konashova, V.F. Konovalov, L.N. Blonskaya, I.G. Sabirzyanov, M.V. Martynova, R.R. Isyanyulova, A.K. Gabdelkhakov // Journal of Engineering and Applied Sciences. 2018. T. 13. № S8. C. 6590-6596.

\section{Сведения об авторах}

1. Иибирдина Лилия Маратовна, кандидат биологических наук, доцент кафедры лесоводства и ландшафтного дизайна, ФГБОУ ВО Башкирский ГАУ, 450001, г. Уфа, ул. 50-летия Октября, 34, e-mail: butomus11@yandex.ru.

2. Блонская Любовь Николаевна, кандидат биологических наук, доцент кафедры лесоводства и ландшафтного дизайна, ФГБОУ ВО Башкирский ГАУ, 450001, г. Уфа, ул. 50-летия Октября, 34, e-mail: 1.n.blonskaya@mail.ru.

3. Тимерьянов Азат Шамилович, кандидат сельскохозяйственных наук, доцент кафедры лесоводства и ландшафтного дизайна, ФГБОУ ВО Башкирский ГАУ, 450001, г. Уфа, ул. 50-летия Октября, 34, e-mail: haf628@yandex.ru.

4. Конашова Светлана Ивановна, доктор сельскохозяйственных наук, профессор кафедры лесоводства и ландшафтного дизайна, 450001, ФГБОУ ВО Башкирский ГАУ, г. Уфа, ул. 50-летия Октября, 34, e-mail: land-s@mail.ru.

5. Муфтахова Светлана Ильдаровна, кандидат сельскохозяйственных наук, ст. преподаватель кафедры лесоводства и ландшафтного дизайна, ФГБОУ ВО Башкирский ГАУ, 450001, г. Уфа, ул. 50-летия Октября, 34, e-mail: muftakhova_s@mail.ru.

Изучена флора газонов города Уфы, представленная 192 видами, относящимися к 31 семейству. По ценотическим и экологическим характеристикам выделено четыре эколого-ценотические группы видов, описанных на площадях, отведенных под газоны. Проведен анализ эколого-ценотических групп по спектрам жизненных форм, гемеробии, активности видов. В сообществах типичных городских газонов со слабым вытаптыванием и хорошим уходом (эколого-ценотическая группа Festuca pratensis) доминируют семейства Poaceae, Asteraceae, Fabaceae, Rosaceae, Apiaceae, преобладают гемикриптофиты и олиго-мезо- $\alpha$-эугемеробы. На газонах, испытывающих значительное антропогенное воздействие (вытаптывание, засоление) (эколого-ценотическая группа Taraxacum officinale), большое количество видов относится к «рудеральным» семействам Polygonaceae, Aste- raceae, Fabaceae, Brassicaceae, Lamiaceae, доминируют гемикриптофиты и мезо-эугемеробы. На площадях, отведенных под устройство газонов, где не произошло развитие злакового сообщества после нарушения почвы (эколого-ценотическая группа Chenopodium album), преобладают рудеральные виды семейств Asteraceae, Poaceae, Amaranthaceae, Lamiaceae, Malvaceae, Polygonaceae, большая доля видов является рудеральными и полурудеральными одно- и двулетниками, $\beta$-эуполигемеробами. На влажных и переувлажненных площадях, отведенных под газоны, также доминируют рудеральные виды семейств Poaceae, Chenopodiaceae, Polygonaceae, значительна доля рудеральных одно- и двулетников $\beta$-эуполигемеробов. В ЭЦГ Тaraxacum officinale, Chenopodium album и Bidens tripartita зарегистрировано большое количество видовнеофитов. Газонные площади с эколого-ценоти- 
ческими группами видов Taraxacum officinale, Chenopodium album и Bidens tripartita являются наиболее засоренными рудералами, необходимо проведение ряда мероприятий для создания сомкнутых травяных покрытий: реконструкция и капитальный ремонт площадей с посевом качественных газонных травосмесей, проведение регулярных укосов для снижения численности рудеральных малолетних видов, своевременные подкормки и полив.

L. Ishbirdina, L. Blonskaya, A. Timeryanov, S. Konashova, S. Muftakhova

\title{
FLORA OF LAWNS IN THE CITY OF UFA
}

\author{
Key words: urban lawns; flora analysis; ecological coenotic groups of species; life form spectrum; hem- \\ eroby; species activity.
}

\section{Authors' personal details}

1. Ishbirdina Liliya, Candidate of Biological Sciences, Associate Professor of the Forestry and Landscape Design Department, Federal State Budgetary Educational Institution of Higher Education «Bashkir State Agrarian University».450001, Ufa, 50-letiya Oktyabrya St., 34, e-mail: butomus11@yandex.ru.

2. Blonskaya Lubov', Candidate of Biological Sciences, Associate Professor of the Forestry and Landscape Design Department, Federal State Budgetary Educational Institution of Higher Education «Bashkir State Agrarian University»,450001, Ufa, 50-letiya Oktyabrya St., 34, e-mail: 1.n.blonskaya@mail.ru.

3. Timeryanov Azat, Candidate of Agricultural Sciences, Associate Professor of the Forestry and Landscape Design Department, Federal State Budgetary Educational Institution of Higher Education «Bashkir State Agrarian University», 450001, Ufa, 50-letiya Oktyabrya St., 34, e-mail: haf628@yandex.ru.

4. Konashova Svetlana, Doctor of Agriculture, Professor of the Forestry and Landscape Design Department, Federal State Budgetary Educational Institution of Higher Education «Bashkir State Agrarian University», 450001, Ufa, 50-letiya Oktyabrya St., 34, e-mail: land-s@mail.ru.

5. Muftakhova Svetlana, Candidate of Agricultural Sciences, Senior Lecturer of the Forestry and Landscape Design Department, Federal State Budgetary Educational Institution of Higher Education «Bashkir State Agrarian University»,450001, Ufa, 50-letiya Oktyabrya St., 34, e-mail: muftakhova_s@mail.ru.

The paper presents a study in the flora of lawns in Ufa. The lawn flora is represented by 192 species belonging to 31 families. Based on coenotic and ecological characteristics, four ecological coenotic groups of species were singled out that were described in the lawn designated areas. The ecological coenotic groups were analysed for life form spectra, hemeroby, species activity. Among the plant communities of typical low-trampled and well-maintained urban lawns (the ecological coenotic group of Festuca pratensis) Poaceae, Asteraceae, Fabaceae, Rosaceae, Apiaceae families were the leading ones, where hemicryptophytes and oligo-meso- $\alpha$ euhemerobes dominated. The lawns subjected to significant anthropogenic impact (trampling, salinization) (the ecological coenotic group of Taraxacum officinale) had a large number of species that belonged to the «ruderal» Polygonaceae, Asteraceae, Fabaceae, Brassicaceae, Lamiaceae families, where hemicryptophytes and meso-euhemerobes dominated. Ruderal species of Asteraceae, Poaceae, Amaranthaceae, Lamiaceae, Malvaceae, Polygona- ceae families prevailed, with a large share of ruderal and semi-ruderal annual and biennial plants, $\beta$-eupolyhemerobes, in the lawn designated areas where gramineous plant community did not develop after soil disturbance (the ecological coenotic group of Chenopodium album). Ruderal species of Poaceae, Chenopodiaceae, Polygonaceae families with a large portion of ruderal annual and biennial $\beta$-eupolyhemerobes also dominated in humid and waterlogged lawn areas. The ecological ecoenotic groups of Taraxacum officinale, Chenopodium album and Bidens tripartita had a large number of neophyte species. The lawn areas with the ecological coenotic groups of Taraxacum officinale, Chenopodium album and Bidens tripartite were found as most colonized with ruderal plants. A number of measures are required to build dense grass covering: reconstruction and heavy maintenance of lawns combined with sowing quality lawn grass mixtures, regular mowing practices to reduce the number of ruderal hemytherophytes and therophytes, timely plant nutrition and watering.

(с) Ишбирдина Л.М., Блонская Л.Н., Тимерьянов А.Ш., Конашова С.И., Муфтахова С.И. 